314

\title{
Spatial and Temporal Changes of the Greenery of Colombo City
}

\author{
Wickrmasinge L.S. ${ }^{{ }^{*}}$, Ranwala S.M.W. ${ }^{2}$ and Subasinghe S.M.C.U.P. ${ }^{1}$ \\ ${ }^{I}$ Department of Forestry and Environmental Science, Faculty of Applied Sciences, University of Sri \\ Jayewardenepura, Nugegoda, Sri Lanka \\ ${ }^{2}$ Department of Plant Sciences, University of Colombo, Colombo 03, Sri Lanka \\ *sudheeraranwala@gmail.com
}

\begin{abstract}
Plans for landscaping of the City of Colombo are now in place and it is of timely important to study the spatial distribution of the vegetation cover and its pattern of change occurred through the past to identify the priority areas for restoring and revitalizing the greenery. This study was therefore focused on mapping the vegetation cover in 47 Wards of the Colombo City for the years of 1956, 1982, 2001 and 2010 using aerial photographs and IKONOS satellite maps. The present work was also involved the evaluation of the percentage extents of vegetation cover and its rates of change in each Ward.
\end{abstract}

According to the resultant maps, a gradual decline of green cover percentage was depicted for the study period. The green cover of the study area was $35.7 \%, 32.2 \%, 31.5 \%$ and $22.2 \%$ in 1956, 1982, 2001 and 2010 respectively. In 2010, the highest green cover (49.65\%) was reported from Narahenpita Ward and only three other Wards (Kirulapona, Cinnamon Gardens, and Thimbirigasyaya) showed the green cover above 30\%. Ten Wards (Kochchikade North, Kochchikade South, Grandpass North, Masangasweediya, Panchikawatte, Fort, Gintupitiya, New Bazar, Maligakanda, Aluthkade East) had green cover less than $10 \%$ in 2010.

The per capita green cover in 13 Wards did not comply with the World Health Organization Standard for urban green spaces. Expansion of built-up areas and road network can be identified as the major reasons for the gradual reduction of green cover in the City of Colombo.

The study also highlights the necessity of a well-planned strategy for upgrading the green cover in the study area. Planting of trees and grasses in public and private lands, increasing public awareness on economic value of green spaces as well as implementation of a participatory tree maintenance programme would be mandatory for the sustainability of the city's greenery.

Keywords: Colombo city, Greenery, Vegetation cover, Green spaces, Satellite image analysis 